OPEN ACCESS

Edited by: Eleonore Fröhlich,

Medical University of Graz, Austria

Reviewed by:

Eid I. Brima,

King Khalid University, Saudi Arabia

Orish Ebere Orisakwe,

University of Port Harcourt, Nigeria

*Correspondence:

Meihua Yang

yangmeihua15@hotmail.com

Specialty section:

This article was submitted to

Predictive Toxicology,

a section of the journal

Frontiers in Pharmacology

Received: 05 June 2017 Accepted: 10 July 2017

Published: 25 July 2017

Citation:

Luo J, Han X, Dou X, Zhang L, Yang $S$ and Yang $M(2017)$ Accumulation of Arsenic Speciation and In Vivo Toxicity Following Oral Administration of a Chinese Patent

Medicine Xiao-Er-Zhi-Bao-Wan

in Rats. Front. Pharmacol. 8:491.

doi: 10.3389/fphar.2017.00491

\section{Accumulation of Arsenic Speciation and In Vivo Toxicity Following Oral Administration of a Chinese Patent Medicine Xiao-Er-Zhi-Bao-Wan in Rats}

\author{
Jiaoyang Luo', Xu Han ${ }^{1,2}$, Xiaowen Dou' ${ }^{1}$ Lei Zhang ${ }^{1}$, Shihai Yang ${ }^{2}$ and Meihua Yang ${ }^{1 *}$ \\ ${ }^{1}$ Institute of Medicinal Plant Development, Chinese Academy of Medical Sciences and Peking Union Medical College, \\ Beijing, China, ${ }^{2}$ College of Traditional Chinese Medicine, Jilin Agricultural University, Changchun, China
}

Realgar-containing traditional Chinese medicines such as Xiao-Er-Zhi-Bao-Wan (XEZBW), have been widely used for thousands of years. However, events associated with arsenic-induced ailments have increasingly become a public concern. To address the toxicity of XEZBW, we studied the histopathology and blood biochemistry of rats exposed to XEZBW using technology like high-performance liquid chromatographyinductively coupled mass spectrometry to determine arsenic speciation. Our results demonstrated that dimethylarsinic acid (DMA) increased from $18.57 \pm 7.45$ to $22.74 \pm 7.45 \mathrm{ng} / \mathrm{g}$ in rat kidney after oral administration for 7 and 14 days, which was 10-fold higher than the levels observed in controls. Trivalent arsenite As(III) showed a large increase on day 7 (26.99 $\pm 1.98 \mathrm{ng} / \mathrm{g})$, followed by a slight decrease on day 14 (13.67 $\pm 6.48 \mathrm{ng} / \mathrm{g})$. Total arsenic levels on day $7(185.52 \pm 24.56 \mathrm{ng} / \mathrm{g})$ and day $14(198.57 \pm 26.26 \mathrm{ng} / \mathrm{g})$ were nearly twofold higher than that in the control group (92.77 $\pm 14.98 \mathrm{ng} / \mathrm{g})$. Histopathological analysis showed mild injury in the liver and kidney of rats subjected to oral administration of realgar for 14 days. As in the XEZBW groups, a mild injury in these organs was observed after administration for 14 days. This study inferred that the toxicity of arsenic was concentration- and time-dependent. The accumulation of DMA, a byproduct of choline metabolism, was responsible for inducing higher toxicity. Therefore, we concluded that measuring the levels of DMA, instead of total arsenic, might be more suitable for evaluating the toxicity of realgar-containing traditional Chinese medicines.

Keywords: Xiao-Er-Zhi-Bao-Wan, arsenic speciation, toxicity, histopathology, blood biochemistry

\section{INTRODUCTION}

Realgar $\left(\mathrm{As}_{4} \mathrm{~S}_{4}\right)$, as one of the widely used traditional Chinese medicines (TCMs), has been prescribed in combination with other herbal medicines to treat common colds, tonsillitis, spasms, ulcers, heat stroke, and coma in China (Wang et al., 2008; Pharmacopoeia of China, 2015) and India (Kumar et al., 2006). Furthermore, in recent years, realgar, in the form of both TCMs and western medicines, has been used for the treatment of hematologic malignancies (Zhang et al., 2009; Liu et al., 2015) for adults and infants. 
Arsenic is known for its toxicity, and the toxicity of realgarcontaining TCMs has also been reported to lead to symptoms such as realgar-induced renal injury (Tsai et al., 2008), which has led to increase in public concern (Cooper et al., 2007; Saper et al., 2008). Furthermore, use of these traditional medicines is forbidden in the United States and in Europe due to the presence of arsenic that is much higher than the allowed limits (Liu et al., 2008a,b). To some extent, the potential toxicity of realgar not only slowed down the international adoption of TCMs, but also restricted medical innovation and development.

To date, opinions regarding the toxicity of arsenic are two-sided. One side argues that realgar should be used as a complementary and alternative medicine, and that if realgar is removed from arsenic-containing TCMs, these drugs would no longer be toxic. However, several studies have indicated that the therapeutic effects of these medicines reduce when realgar is removed (Fang et al., 2007; Fu et al., 2007). Previous studies also verified that realgar is one of the active components in An-GongNiu-Huang-Wan (AGNH), which helps prevent LPS-induced neuroinflammation in microglia-neuron cultures (Zhang et al., 2010, 2012). Another side of the opinion argues that the toxicity of arsenic depends on its chemical form and concentration in the biological systems (Cao et al., 2014; Contreras-Acuña et al., 2014). For example, arsenic in the form of sulfides $\left(\mathrm{As}_{2} \mathrm{~S}_{2}\right.$ or $\mathrm{As}_{4} \mathrm{~S}_{4}$ ) is indiscerptible in water (only $4 \%$ is bioavailable in physiological gastric juice or intestinal fluids (Koch et al., 2007), therefore, it is much less acutely toxic than arsenite and arsenate (Lu et al., 2011a,b,c). However, it is still unclear whether realgarcontaining TCMs are safe for long-term use. In addition, arsenic accumulation as related to variation in morphology of diseases has yet to be investigated.

The purpose of the present study was to investigate the accumulation of arsenic speciation in rat tissues and evaluate the in vivo toxicity. Since the toxicity of different forms of arsenic is variable, arsenic speciation in tissues should be determined prior to evaluating the toxicity of realgar-containing TCMs. In this study, Xiao-Er-Zhi-Bao-Wan (XEZBW), a realgar-containing TCM (3.6\% realgar, w/w), which has been widely used to treat infant vomiting, diarrhea, and cold, was investigated. By using high-performance liquid chromatography-inductively coupled mass spectrometry (HPLC-ICP-MS), different arsenic speciation in liver and kidney of rats was determined. The histopathology and blood biochemistry in these rats were further investigated to supplement any elucidation of the potential relationship between the accumulation of an arsenic speciation in vivo and its toxicity.

\section{MATERIALS AND METHODS}

\section{Instrumentation and Reagents}

An Agilent 7500ce ICP-MS (Palo Alto, CA, United States) with collision cell was applied for element specific detection coupled with an Agilent 1100 HPLC for chromatographic separations. A liquid chromatography (LC) system comprised of Hamilton PRP-X100 anion-exchange column $(250 \mathrm{~mm} \times 4.1 \mathrm{~mm}$ I.D., $10 \mu \mathrm{m})$ was used as the chromatographic system. The homogenate was prepared using T18 digital ULTRA-TURRAX
(IKA, Germany). Infinite M1000 multimode microplate reader (TECAN, Switzerland) and UV-Vis spectrophotometer (Agilent, United States) were used for analyzing blood biochemistry. A TGL16M hydro-extractor was used to centrifuge samples. The optimum ICP-MS conditions were summarized as follows, RF power: 1,500 W; plasma Ar flow rate: $15 \mathrm{~L} / \mathrm{min}$; make up Ar flow rate: $1 \mathrm{~L} / \mathrm{min}$; carrier Ar flow rate: $1 \mathrm{~L} / \mathrm{min} ; \mathrm{H}_{2}$ flow rate: $3.5 \mathrm{~mL} / \mathrm{min}$; He flow rate: $4 \mathrm{~mL} / \mathrm{min}$. The mobile phase was prepared using $0.025 \mathrm{~mol} / \mathrm{L}$ ammonium dihydrogen phosphate solution (A) and ultrapure water (B), the forms were separated by a gradient elution program: $20-20 \%(\mathrm{v} / \mathrm{v}) \mathrm{B}$ at $1.0-2.0 \mathrm{~min}$; $20-70 \% \mathrm{~B}$ at $2.0-7.0 \mathrm{~min} ; 70-99 \% \mathrm{~B}$ at $7.0-10.0 \mathrm{~min} ; 99-20 \% \mathrm{~B}$ at $10.0-12.0 \mathrm{~min} ; 20-20 \% \mathrm{~B}$ at $12.0-14.0 \mathrm{~min}$.

All reagents were of at least analytical-reagent grade purity. The prepared working solutions of As(III), DMA, MMA, and $\mathrm{As}(\mathrm{V})$ were diluted from the stock solution (the concentrations of each forms were $124.3,97.4,46.2$, and $32.4 \mu \mathrm{g} / \mathrm{g}$ ) purchased from the National Center for Reference Materials (NCRM, Beijing, China) with ultra-pure water $\left(18.2 \mathrm{M} \Omega \mathrm{cm}^{-1}\right)$ obtained from a Milli-Q (Millipore, United States) system. Working solutions of total arsenic were prepared by stepwise dilution of the stock solution obtained from the NCRM with nitric acid (3\%, v/v). Rat aspartate aminotransferase (AST) ELISA kit and rat creatinine ELISA kit were purchased from Shanghai Weifan Biotechnology Co., Ltd. (Shanghai, China). Blood urea nitrogen (BUN) kit and alanine aminotransferase (ALT) were purchased from Nanjing Jiancheng Bioengineering Institute (Nanjing, China).

\section{Animals}

This study was carried out in accordance with the recommendations of the Institutional Animal Care and Use Guidelines in China. The protocols were approved by the Institutional Animal Care of Medicinal Plant Development, Chinese Academy of Medical Sciences. The male SpragueDawley rats (180-220 g) (Fang et al., 2007; Zhang et al., 2010) were purchased from the Beijing HFK Bioscience Co., Ltd. (Beijing, China). Before the experiments, the rats were kept under standard laboratory conditions (12/12 h light/darkness, $20 \pm 2^{\circ} \mathrm{C}, 60 \pm 5 \%$ humidity) for 1 week and fasted for $12 \mathrm{~h}$ with free access to water prior to the experiments.

The arsenic accumulation experiment was performed as follows. First, 33 rats were randomized into six groups: control group (three rats for day 0), low dosage XEZBW (1250 mg/kg) groups (six rats for 1 week and six rats for 2 weeks), high dosage XEZBW (3750 mg/kg) group (six rats for 2 weeks), and realgar ( $45.25 \mathrm{mg} / \mathrm{kg}$ ) groups (six rats for 1 week and six rats for 2 weeks). Blood samples of about $0.5 \mathrm{~mL}$ were withdrawn from the tail of rats into heparinized polythene tubes before the animals were sacrificed. Plasma was separated by centrifugation at $5000 \mathrm{rpm}$ for $5 \mathrm{~min}$ and stored at $4^{\circ} \mathrm{C}$ until analysis. The visceral organ samples were obtained after 7 and 14 days of administration, and stored at $-80^{\circ} \mathrm{C}$ until analysis.

\section{Blood Biochemistry}

Plasma was separated from the whole blood of rats by centrifugation at $5000 \mathrm{rpm}$ for $5 \mathrm{~min}$. Using multimode microplate reader and UV-V is spectrophotometer, the activities 
of AST, ALT, BUN, and creatinine were measured following instructions provided in test kits.

\section{Determination of Total Arsenic}

Each accurately weighed visceral organ sample was mixed with an aliquot of $5 \mathrm{~mL}$ ultra-pure water, then the mixture was mashed into homogenate. To determine the amount of total arsenic, the homogenate was combined with $8 \mathrm{~mL}$ concentrated $\mathrm{HNO}_{3}$ and $2 \mathrm{~mL}$ concentrated $\mathrm{HCl}$ in pre-cleaned teflon vessels, then the sample was digested completely under the optimum parameter condition using a microwave accelerated reaction system. After digestion, the sample was diluted with $\mathrm{HNO}_{3}(3 \%, v / v)$ to $50 \mathrm{~mL}$ for ICP-MS [the kinetic energy discrimination model (KED) was used for arsenic detection] analysis.

\section{Determination of Arsenic Speciation in Visceral Organ Sample}

To determine the arsenic speciation, the homogenate was vortexmixed for $1 \mathrm{~min}$ and ultrasound-assisted for $10 \mathrm{~min}$, then centrifuged at $15,000 \times g$ at, $4^{\circ} \mathrm{C}$ for $50 \mathrm{~min}$. The supernatant was filtered through a $0.22 \mu \mathrm{m}$ polytetrafluoroethylene (PTFE) millipore film before it was injected for HPLC-ICP-MS analysis.

\section{Histological Evaluation}

Portions of the liver and kidney were removed, weighed, and fixed in $10 \%$ neutral buffered formalin. Then, the fixed tissues were paraffin embedded, processed by standard histology procedures, sectioned at $6 \mu \mathrm{m}$ and stained with hematoxylin and eosin (H\&E). Pathological assessments were done in a blind fashion. Incidence of hepatic and renal lesions was determined by histological analysis of the longitudinal midline section of the right kidney and the same portion of the liver from each animal.

\section{Statistical Analysis}

Data was calculated as mean and standard error. The SPSS 20 software was used for statistical analysis, the significance of variation between groups in data were analyzed using a one-way analysis of variance (ANOVA), followed by Duncan's multiple range test. The significant level was set at $p<0.05$ in all cases.

\section{RESULTS}

All rats survived the entire process of oral administration of XEZBW and realgar. No apparent clinical symptoms were observed.

\section{Arsenic Quantification in Visceral Organ Sample}

To delineate the potential hepatotoxicity and nephrotoxicity, arsenic contents in kidney and liver were first determined by HPLC-ICP-MS. Figure 1 shows arsenic speciation accumulation in the kidney $2 \mathrm{~h}$ after the last oral dose.

Renal total arsenic contents in 1 week $(185.52 \pm 24.56 \mathrm{ng} / \mathrm{g})$ and 2 weeks of administration ( $198.57 \pm 26.26 \mathrm{ng} / \mathrm{g}$ ) were nearly twofold higher than the control group $(92.77 \pm 14.98 \mathrm{ng} / \mathrm{g})$.

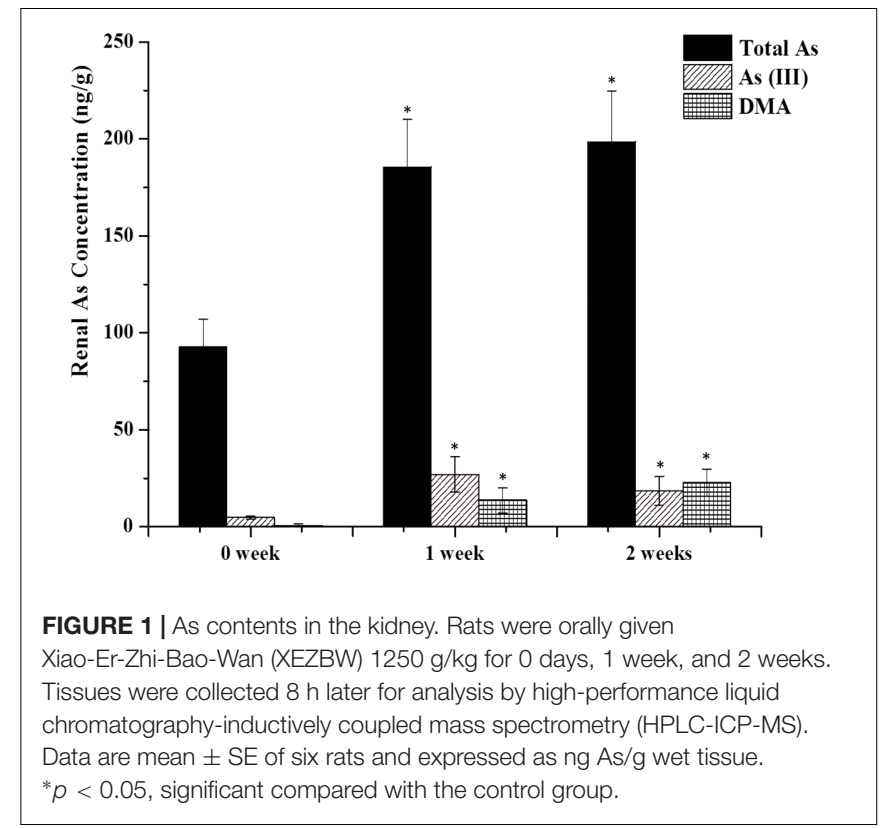

No pentavalent arsenate $\mathrm{As}(\mathrm{V})$ and monomethylarsononous acid (MMA) forms were detected in either the treatment or the control groups. In the control group, trivalent arsenite As(III) was observed (4.78 $\pm 1.98 \mathrm{ng} / \mathrm{g})$ while dimethylarsinic acid (DMA) was barely present. In treatment groups, DMA increased to $18.57 \pm 7.45 \mathrm{ng} / \mathrm{g}$ after 1 week, and continued to increase to $22.74 \pm 7.45 \mathrm{ng} / \mathrm{g}$ at 2 weeks. As(III) also increased to $26.99 \pm 1.98 \mathrm{ng} / \mathrm{g}$ after 1 week while decreased to $13.67 \pm 6.48 \mathrm{ng} / \mathrm{g}$ at 2 weeks.

As shown in Figure 2, arsenic speciation accumulated in the liver $2 \mathrm{~h}$ after the last oral administration and total arsenic level were also increased (twofold over controls). No trace of As(V) and MMA forms were detected in either the treatment or the control group. In the control group, no DMA was detected and the content of As(III) was $4.78 \pm 0.63 \mathrm{ng} / \mathrm{g}$. However, after 1 week of treatment, As(III) and DMA increased to $37.77 \pm 8.75$ and $4.77 \pm 2.45 \mathrm{ng} / \mathrm{g}$, respectively. Total arsenic level also increased to $130.56 \pm 17.51 \mathrm{ng} / \mathrm{g}$. After treatment for 2 weeks, DMA showed a gradual increase $(6.87 \pm 2.08 \mathrm{ng} / \mathrm{g})$, however, As(III) and total arsenic exhibited a slight decrease $(30.67 \pm 1.23$ and $155.91 \pm 40.21 \mathrm{ng} / \mathrm{g}$ ) compared to results after 1 week of treatment.

\section{Blood Biochemistry}

To evaluate the potential hepatotoxicity and nephrotoxicity of XEZBW, we assayed biomarkers such as BUN, creatinine, AST and serum ALT, and the results were illustrated in Figure 3. ALT and AST are well-known markers of liver injury. In this study, no significant change in ALT and AST $(p>0.05)$ was observed after oral administration of $1250 \mathrm{mg} / \mathrm{kg}$ XEZBW $(66.20 \pm 12.40 \mathrm{U} / \mathrm{L}$ and $136.90 \pm 12.60 \mathrm{U} / \mathrm{L}$ on day $7 ; 67.17 \pm 8.65 \mathrm{U} / \mathrm{L}$ and $143.99 \pm 20.39 \mathrm{U} / \mathrm{L}$, on day 14) compared to control group $(47.72 \pm 9.86 \mathrm{U} / \mathrm{L}$ and $124.96 \pm 14.67 \mathrm{U} / \mathrm{L})$. BUN and creatinine are biomarkers of renal injury. Figure 3 showed that on day 


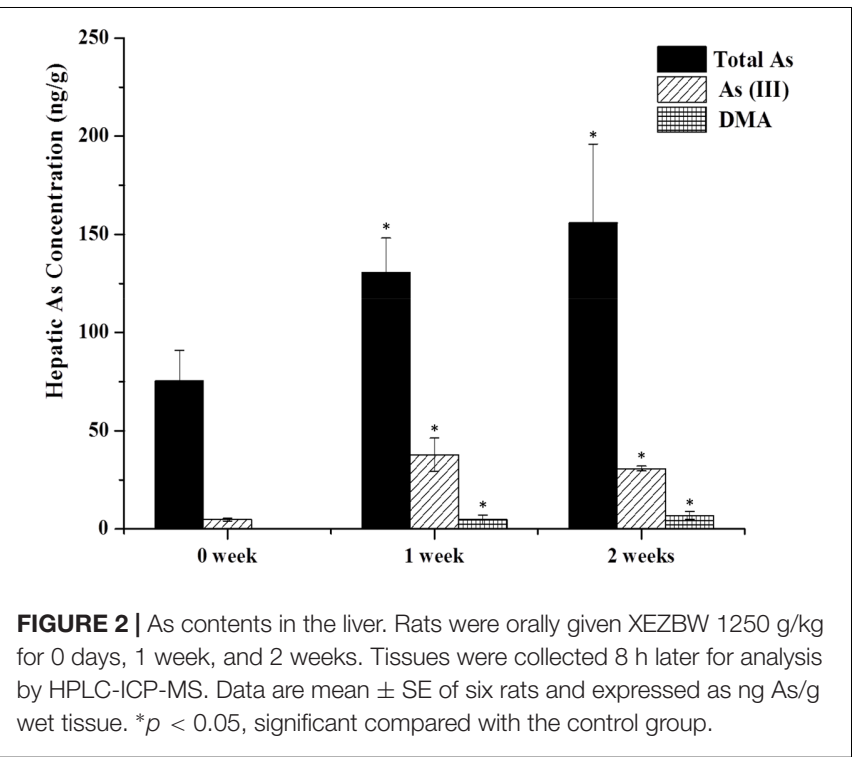

7 after oral administration of $1250 \mathrm{mg} / \mathrm{kg}$ XEZBW, BUN was significantly increased $(12.98 \pm 1.50 \mathrm{mmol} / \mathrm{L})$, followed by a decrease on day $14(6.87 \pm 1.51 \mathrm{mmol} / \mathrm{L})$ compared to control group $(9.03 \pm 1.67 \mathrm{mmol} / \mathrm{L})$. Meanwhile, no significant change in creatinine $(p>0.05)$ after both 1 week $(37.83 \pm 2.45 \mu \mathrm{mol} / \mathrm{L})$ and 2 week administration $(39.12 \pm 3.84 \mu \mathrm{mol} / \mathrm{L})$ compared to control group $(37.86 \pm 3.72 \mu \mathrm{mol} / \mathrm{L})$ was observed.

\section{Histopathology}

Results of histopathological analysis are shown in Figure 4. Kidneys from the XEZBW 1 week group exhibited nearly normal appearance; the glomeruli were intact, while proximal tubular cells were slightly swollen, foci of tubular vacuolation and degeneration were observed. Renal tubular damage after oral administration of h-XEZBW (threefolds over clinical dose) was the most severe among all groups.

After oral administration for 2 weeks (including both XEZBW and h-XEZBW groups), foci of blood cysts from tubular necrosis were observed. In Figure 4C (oral administration of XEZBW for 2 weeks), mild impairment of nephrocytes and inflammatory cellular infiltration were observed. However, these phenomena were not observed in Figure 4B (oral administration of XEZBW for 1 week). The amounts of total arsenic and DMA in the 2 week group were not larger than those in the 1 week group, which suggests that the levels of total arsenic and DMA in these groups may be the minimal toxic dose for inducing cytopathy.
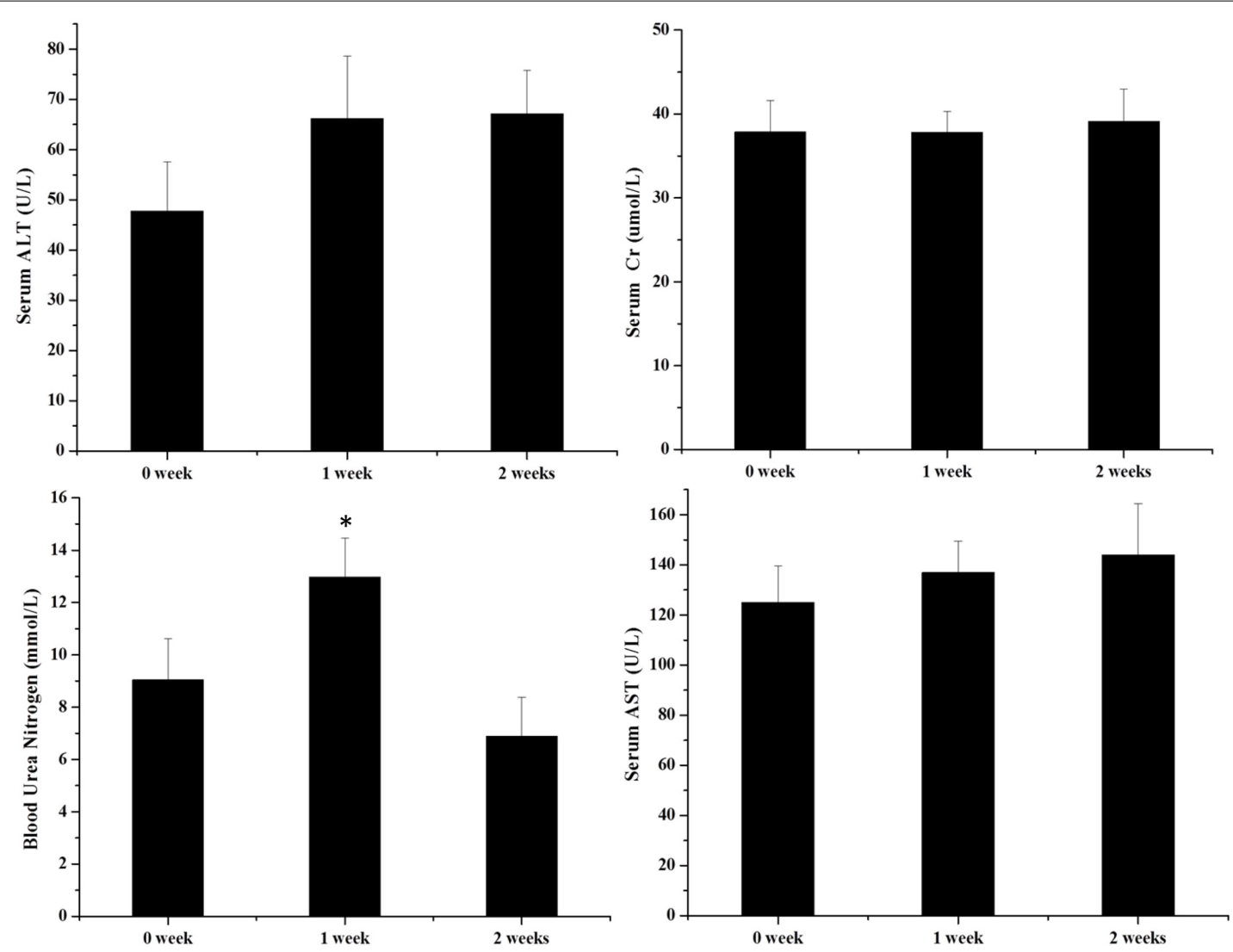

FIGURE 3 | Serum activities of alanine aminotransferase (ALT), serum creatinine, blood urea nitrogen (BUN), and aspartate transaminase (AST). Rats were orally given XEZBW $1250 \mathrm{mg} / \mathrm{kg}$ for 0 days, 1 week, and 2 weeks. Blood was collected $8 \mathrm{~h}$ later for analysis. Data are mean $\pm \mathrm{SE}$ of six rats. $* p<0.05$, significant compared with the control group. 

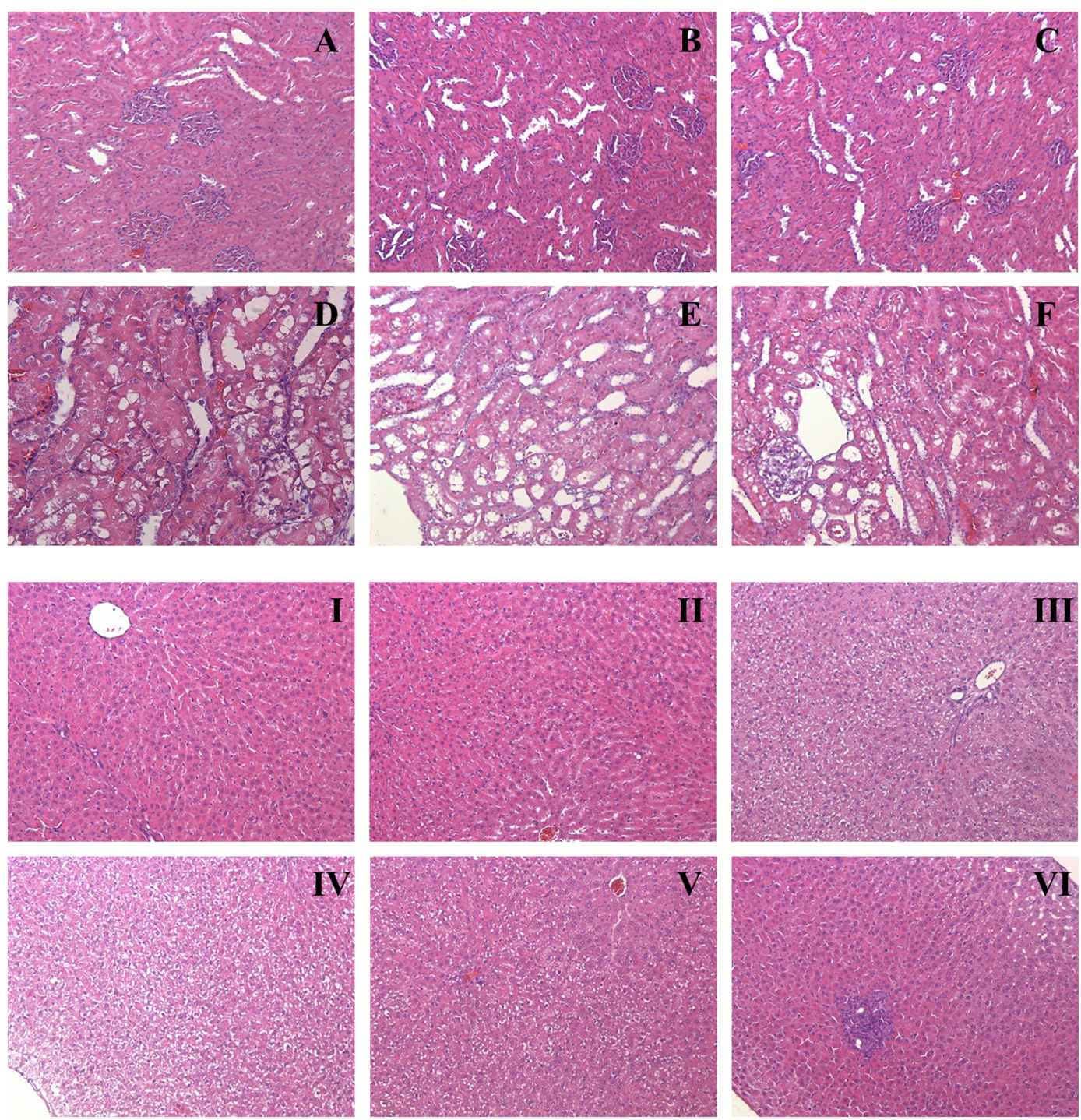

FIGURE 4 | Representative histopathology of kidney (A-F) and liver (I-VI). Rats were orally given XEZBW (1250 mg/kg) for 1 week (B and II) and 2 weeks (C and III), h-XEZBW (3750 mg/kg) for 2 weeks (D and $\mathbf{I V})$, realgar ( $45.25 \mathrm{mg} / \mathrm{kg}$ ) for 1 week (E and $\mathbf{V}$ ) and 2 weeks ( $\mathbf{F}$ and $\mathbf{V} \mathbf{I})$ or distilled water $(\mathbf{A}$ and $\mathbf{I})$. Tissues were fixed in formalin and stained with hematoxylin and eosin (H\&E). Magnitude (100x).

Representative histopathology photos of the liver are shown in Figure 4. Compared to controls, oral administration of XEZBW for 1 week did not lead to any variation in morphology. In contrast, other treatment groups exhibited varying degrees of hepatocyte swelling. Furthermore, foci of inflammation were also observed in oral administration of $45.25 \mathrm{mg} / \mathrm{kg}$ realgar for 2 weeks.

\section{DISCUSSION}

It is generally assumed that the amount of toxicant/metal at the target organ is responsible for toxicity (Lehman-McKeeman, 2010). In order to comprehensively evaluate the toxicity of arsenic-containing TCMs, the metabolism and accumulation of arsenic in tissues need to be investigated. Oral administration of Liu-Shen-Wan (LSW), an arsenic-containing TCM, did not lead to any significant arsenic accumulation compared to the control group in both liver and kidney. In contrast, oral administration of arsenite and arsenate led to significant arsenic accumulation. These results demonstrated that realgar-containing LSW was poorly absorbed and distributed to various tissues and therefore, did not reach a critical concentration to cause any tissue damage as compared to administration of the same amount of arsenic in the forms of arsenite and arsenate (Liu et al., 2011). Lu et al. (2011c) orally administered AGNH, realgar and arsenite to mice, and showed that the accumulation of arsenic after the administration of arsenite was approximately100-fold higher than that in realgar-treated liver (6200 vs. $68 \mathrm{ng} / \mathrm{g}$ ). In addition, the paper argued against the previous assumption 
that herbal ingredients in AGNH would reduce arsenic release and bioavailability (Tang and Wang, 2005). Taken together, the aforementioned studies have proven that realgar and realgarcontaining TCMs are much less toxic than arsenite and arsenate.

In higher animals, the most common inorganic arsenic [As(V) and As(III)] (ATSDR, 2005) is metabolized by oxidative methylation to form MMA(V), which will then be reduced to MMA(III) and then to DMA(V) (Fukai et al., 2006; Thomas, 2007). Since toxicity depends on the forms of heavy metals and deleterious elements [arsenite $\left(\mathrm{LD}_{50}\right), 15 \mathrm{mg} / \mathrm{kg}$; arsenate $\left(\mathrm{LD}_{50}\right), 112-175 \mathrm{mg} / \mathrm{kg}$; MMA $\left(\mathrm{LD}_{50}\right), 700 \mathrm{mg} / \mathrm{kg}$, and DMA $\left(\mathrm{LD}_{50}\right), 2600 \mathrm{mg} / \mathrm{kg}$ ], the quantity of each of these forms accumulated in tissues could be an important biomarker for evaluating arsenic toxicity. In this study, the accumulation of arsenic speciation was investigated in liver and kidney, and only the amounts of As(III) and DMA were determined. Interestingly, in the kidney, DMA progressively increased, while As(III) increased initially then decreased. The change in As(III) levels was different in the kidney compared to that in the liver.

Besides, Lu et al. (2011a) evaluated the hepatotoxicity and blood biochemistry after oral administration of AGNH in mice. Their result showed that both ALT and AST levels in the AGNH group were not significantly different from the controls ( 68 vs. $42 \mathrm{U} / \mathrm{L} ; 380$ vs. $257 \mathrm{U} / \mathrm{L}$ ). In addition, BUN levels were also not elevated after treatment with AGNH (Tang and Wang, 2005). Wei et al. (2009) analyzed rat blood after oral administration of realgar for 3 weeks, and found no significant change in ALT on days 7, 14, and 21 compared to controls $(p>0.05)$. Furthermore, BUN level was obviously higher than controls $(p<0.05)$ only on day 7 . Taken together, these results suggested that oral administration of realgar-containing XEZBW led to little change in blood biochemistry. We could infer from these results that liver and kidney functions probably remained normal after XEZBW administration.

Furthermore, previous work has demonstrated that mercury could exert harmful effect on the kidney through mercurybinding proteins, which are filtered by glomerulus (Pelclova et al., 2002). Pysher et al. (2007) determined that arsenic induces pathological damages in kidney through increasing hexokinase II expression in the renal glomerulus. Our results showed that oral administration of realgar and XEZBW for 2 weeks also induced glomerulus injury.

Comparing the arsenic content in each group, the quantity of arsenic observed after oral administration of XEZBW for 2 weeks was not significantly higher than that of the 1 week group. However, mild toxicity was detected only after 2 weeks of administration. Therefore, we speculated that toxicity is not only related to the quantity of arsenic, but also the time of arsenic exposure. Thomas et al. (2007, 2010) suggested that the methylation of arsenicals, besides being a detox process, could also be a mechanism of toxicity. Byproducts of choline metabolism like creatine, were detected after oral administration of $1 \mathrm{~g} / \mathrm{kg}$ of realgar to rats for 2 weeks (Lu et al., 2011b). Arsenite is much more toxic than DMA in terms of acute poisoning. However, the major toxicity of chronic poisoning comes from the transformation of arsenite to DMA. Therefore, as the accumulation of DMA persists, toxicity increases. In our work, the total arsenic content in the 2 week groups was nearly 2-fold higher than that of the control group; whereas, the DMA content in kidneys was almost 10-fold over that of the controls (which exhibited barely detectable amount of arsenic and DMA in kidney and liver). Other arsenic speciations were not detected. Therefore, determination of DMA content could be more valuable for evaluating the toxicity of realgarcontaining TCMs. Finally, a major type of lesion observed after oral administration of realgar and XEZBW for 2 weeks could lead to hepatitis and glomerular injury. Fortunately, these toxic effects appeared to be reversible, and tissue damages were improved when realgar and XEZBW treatments were terminated.

\section{CONCLUSION}

In this study, arsenic speciation concentrations were analyzed in conjunction with histopathology and blood biochemistry to assess the toxicity of XEZBW. Renal and hepatic total arsenic contents in treatment groups were nearly twofold higher than the control group, while renal DMA displayed a continuous increase. Histopathology results showed that mild injuries in liver and kidney after oral administration of realgar for 2 weeks. A much milder injury was observed in kidney after oral administration of XEZBW for 2 weeks. Our results suggested that the continuous accumulation (after oral administration of realgar for 2 weeks or longer) of low dose of arsenic could lead to mild kidney injury, therefore, realgar-containing medicines should not be recommended for long-term use.

\section{AUTHOR CONTRIBUTION}

JL and MY designed the study; XH, JL, and LZ performed the experiments; JL and XD analyzed the data; JL and XH wrote the paper; MY and SY revised the paper.

\section{ACKNOWLEDGMENTS}

Financial support for this work from the PUMC Youth Fund and Fundamental Research Funds for the Central Universities (3332015143), Special Research Grant for Nonprofit Public Service (2015468004-4), and CAMS Innovation Fund for Medical Sciences (2016-I2M-3-010) is gratefully acknowledged. 


\section{REFERENCES}

ATSDR (2005). Toxicological Profile for Arsenic, Agency for Toxic Substances and Disease Registry, Atlanta, GA.

Cao, Y., Duan, J. A., Guo, J. M., Li, W. X., and Tao, W. W. (2014). Pharmacokinetic properties of arsenic species after oral administration of Sargassum pallidum extract in rats using an HPLC-HG-AFS method. J. Pharmaceut. Biomed 96, 213-219. doi: 10.1016/j.jpba.2014.03.045

Contreras-Acuña, M., García-Barrera, T., García-Sevillano, M. A., and Gómez-Ariza, J. L. (2014). Arsenic metabolites in human serum and urine after seafood (Anemonia sulcata) consumption and bioaccessibility assessment using liquid chromatography coupled to inorganic and organic mass spectrometry. Microchem. J 112, 56-64. doi: 10.1016/j.microc.2013. 09.007

Cooper, K., Noller, B., Connell, D., Yu, J., Sadler, R., Olszowy, H., et al. (2007). Public health risks from heavy metals and metalloids present in traditional Chinese medicines. J. Toxicol. Env. Heal. A 70, 1694-1699. doi: 10.1080/ 15287390701434885

Fang, F., Sun, J. N., Yang, L., and Yang, Z. Y. (2007). Effects of An-Gong-Niu-Huang pills and its simplified prescription on intracerebral hemorrhage injury in rats. J. Beijing Univ. Tradit. Chin. Med 39, 611-613.

Fu, X. W., Zao, J. Z., and Wang, S. (2007). Study the effect of An-Gong-Niu-huang pill on rats with experimental intracerebral hemorrhage during acute period on the expression of amino acids and ultrastructure around hematoma. Hebei Med 13, 224-225.

Fukai, Y. S., Hirata, M. Y., Ueno, M. Y., Ichikawa, N. K., Kobayashi, H. K., Saitoh, H. S., et al. (2006). Clinical Pharmacokinetic Study of Arsenic Trioxide in an Acute Promyelocytic Leukemia (APL) Patient: Speciation of Arsenic Metabolites in Serum and Urine. Biol. Pharm. Bull 5, 1022-1027. doi: 10.1248/ bpb.29.1022

Koch, I., Sylvester, S., Lai, V. W., Owen, A., Reimer, K. J., and Cullen W. R. (2007). Bioaccessibility and excretion of arsenic in Niu Huang Jie Du Pian pills. Toxicol. Appl. Pharm 222, 357-364. doi: 10.1016/j.taap.2006.12.005

Kumar, A., Nair, A. G., Reddy, A. V., and Garg, A. N. (2006). Bhasmas: unique ayurvedic metallic-herbal preparations, chemical characterization. Biol. Trace Elem. Res 109, 231-254. doi: 10.1385/BTER:109:3:231

Lehman-McKeeman, L. (2010). Paracelsus and formaldehyde 2010: the dose to the target organ makes the poison. Toxicol. Sci 116, 361-363. doi: 10.1093/toxsci/ $\mathrm{kfq} 164$

Liu, J., Liang, S. X., Yuan, F. L., Jia, W. M., Wu, Q., and Shi, J. S. (2011) Realgar and realgar-containing Liu-Shen-Wan are less acutely toxic than arsenite and arsenate. J. Ethnopharmacol 134, 26-31. doi: 10.1016/j.jep.2010. 11.052

Liu, J., Lu, Y. F., Wu, Q., Goyer, R. A., and Waalkes, M. P. (2008a). Mineral arsenicals in traditional medicines: orpiment, realgar, and arsenolite, J. Pharmacol. Exp. Ther 326, 363-368. doi: 10.1124/jpet.108.139543

Liu, J., Shi, J. Z., Yu, L. M., Goyer, R. A., and Waalkes, M. P. (2008b). Mercury in traditional medicines: is cinnabar toxicologically similar to common mercurials? Exp. Biol. Med 233, 810-817. doi: 10.3181/0712-MR-336

Liu, Y., He, P., Cheng, X., and Zhang, M. (2015). Long-term outcome of 31 cases of refractory acute promyelocytic leukemia treated with compound realgar natural indigo tablets administered alternately with chemotherapy. Oncol. Lett 2, 1184-1190. doi: 10.3892/ol.2015.3308

Lu, Y. F., Wu, Q., Liang, S. X., Miao, J. W., Shi, J. S., and Liu, J. (2011a). Evaluation of hepatotoxicity potential of cinnabar containing An-Gong-Niu-Huang Wan, a patent traditional Chinese medicine. Regul. Toxicol. Pharm 2, 206-211. doi: 10.1016/j.yrtph.2011.03.007

Lu, Y. F., Wu, Q., Yan, J. W., Shi, J. Z., Liu, J., and Shi, J. S. (2011b). Realgar, cinnabar and An-Gong-Niu-Huang Wan (AGNH) are much less chronically nephrotoxic than common arsenicals and mercurial. Exp. Biol. Med 2, 233-239. doi: $10.1258 /$ ebm. 2010.010247
Lu, Y. F., Yan, J. W., Wu, Q., Shi, J. Z., Liu, J., and Shi, J. S. (2011c). Realgar- and cinnabar-containing An-Gong-Niu-Huang Wan (AGNH) is much less acutely toxic than sodium arsenite and mercuric chloride. Chemico-Biol. Interact 189, 134-140. doi: 10.1016/j.cbi.2010.11.006

Pelclova, D., Lukáš, E., Urban, P., Preiss, J., Ryšavá, R., Lebenhart, P., et al. (2002). Mercury intoxication from skin ointment containing mercuric ammonium chloride. Int. Arch. Occ. Env. Hea 1, 54-59. doi: 10.1007/s00420-002-0349-x

Pharmacopoeia of China (2015). Pharmacopoeia of the People's Republic of China. Beijing, Chemical Industry Press.

Pysher, M. D., Sollome, J. J., Regan, S., Cardinal, T. R., Hoying, J. B., Brooks, H. L., et al. (2007). Increased hexokinase II expression in the renal glomerulus of mice in response to arsenic. Toxicol. Appl. Pharm 224, 39-48. doi: 10.1016/j.taap. 2007.06.019

Saper, R. B., Phillips, R. S., Sehgal, A., Khouri, N., Davis, R. B., Paquin, J., et al. (2008). Lead, mercury, and arsenic in US- and Indian- manufactured Ayurvedic medicines sold via the Internet. JAMA 300, 915-923. doi: 10.1001/jama.300.8.915

Tang, Y. S., and Wang, L. S. (2005). Pharmacokinetic studies of arsenic-containing traditional medicines. Zhong Yao Cai 12, 1130-1135. doi: 10.13863/j.issn10014454.2005.12.038

Thomas, D. J. (2007). Molecular processes in cellular arsenic metabolism. Toxicol. Appl. Pharm 222, 365-373. doi: 10.1016/j.taap.2007.02.007

Thomas, D. J., Li, J., Waters, S. B., and Xing, W. (2007). Arsenic (+3 oxidation state) methyltransferase and the methylation of arsenicals. Exp. Biol. Med 1, 3-13.

Thomas, D. J., Nava, G. M., Cai, S.-Y., Boyer, J. L., Hernández-Zavala, A., and Gaskins, H. R. (2010). Arsenic (+3 Oxidation State) Methyltransferase and the Methylation of Arsenicals in the Invertebrate Chordate Ciona intestinalis. Toxicol. Sci. 113, 70-76. doi: 10.1093/toxsci/kfp250

Tsai, C. H., Tsan, Y. T., and Hung, D. Z. (2008). Herbal preparation of realgar induces acute renal failure. Clin. Toxicol. (Phila.) 46, 919-920. doi: 10.1080/ 15563650802293992

Wang, L., Zhou, G. B., Liu, P., Song, J. H., Liang, Y., Yan, X. J., et al. (2008). Dissection of mechanisms of Chinese medicinal formula realgar-indigo naturalis as an effective treatment for promyelocytic leukemia. P. Nalt. Acad. Sci. USA 105, 4826-4831. doi: 10.1073/pnas.0712365105

Wei, L., Liao, P. Q., Wu, H. F., Li, X. J., Pei, F. K., and Li, W. S. et al. (2009). Metabolic profiling studies on the toxicological effects of realgar in rats by 1H NMR spectroscopy. Toxicol. Appl. Pharm 234, 314-325. doi: 10.1016/j.taap. 2008.11.010

Zhang, F., Liu, J., and Shi, J.-S. (2010). Effect of Angong Niuhuang Wan, cinnabar and realgar against lipopolysaccharide-mediated neurotoxicity. Chin. J. Pharmacol. Toxicol. 24, 161-167. doi: 10.3867/j.issn.1000-3002.2010.03.001

Zhang, F., Lu, Y. F., Wu, Q., Yan, J. W., Shi, J. S., and Liu, J. (2012). Role of cinnabar and realgar of WSHFD in protecting against LPS-induced neurotoxicity. J. Ethnopharmacol 139, 822-828. doi: 10.1016/j.jep.2011.12.026

Zhang, Q. Y., Mao, J. H., Liu, P., Huang Q. H., Lu, J., Xie, Y. Y., et al. (2009) A systems biology understanding of the synergistic effects of arsenic sulfide and Imatinib in BCR/ABL-associated leukemia. Proc. Nalt. Acad. Sci. USA 106, 3378-3383. doi: 10.1073/pnas.0813142106

Conflict of Interest Statement: The authors declare that the research was conducted in the absence of any commercial or financial relationships that could be construed as a potential conflict of interest.

Copyright (c) 2017 Luo, Han, Dou, Zhang, Yang and Yang. This is an open-access article distributed under the terms of the Creative Commons Attribution License (CC BY). The use, distribution or reproduction in other forums is permitted, provided the original author(s) or licensor are credited and that the original publication in this journal is cited, in accordance with accepted academic practice. No use, distribution or reproduction is permitted which does not comply with these terms. 